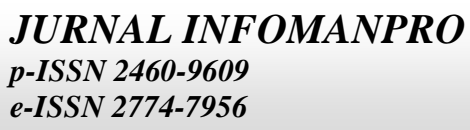

https://ejournal.itn.ac.id/index.php/infomanpro vol.10 No.1 Tahun 2021 , pp. 11-15

\title{
BANTUAN TEKNIS PEMBUATAN SUMUR INJEKSI UNTUK KONSERVASI MATA AIR DI DESA PETUNGSEWU
}

\author{
Lies K Wulandari ${ }^{1, a}$, Kustamar ${ }^{1}$, Hirianto, dan Hery Setyobudiarso ${ }^{1}$ \\ 1,2.3,4Dosen Jurusan Teknik Sipil Institut Teknologi Nasional Malang
}

\begin{abstract}
ABSTRAK
Beberapa bagian penting dalam pembuatan Sumur Injeksi ialah: penentuan lokasi, penentuan dimensi sumur, penentuan diameter pipa injeksi, dan penentuan system filtrasi. Lokasi yang tepat akan menjamin terkumpulnya air hujan yang cukup dan injeksi yang tepat sasaran. Dimensi sumur dan diameter pipa injeksi yang tepat akan mendapatkan valume tampungan yang efektif, karena seimbang antara debit air hujan yang masuk sumur dan debit air yang diinjeksikan ke lapisan aquifer. Sistem filtrasi yang tepat akan menjamin kualitas air dan laju aliran yang sesuai. Desa Petung sewu, Kecamatan Wagir, Kabupaten Malang, terletak di sisi timur lereng Gunung Kawi, dengan topografi yang berbukit-bukit. Wilayah administrasi meliputi Dusun: Sengonrejo, Codo, Petungsewu, Codo Ledok, dan Durenan. Jumlah penduduk Desa Petungsewu tahun 2018 adalah 4491 Jiwa dengan jumlah kk 1315, dan mayoritas berprofesi sebagai petani. Kebutuhan air bersih dilayani dengan memanfaatkan sumber - sumber air di beberapa anak sungai, yang dialirkan secara terpisah ke masing-masing dusun, sesuai dengan kondisi topografinya. Kabutuhan air penduduk Dusun Durenan dilayani dengan perpipaan dari Sumber Air di alur sungai Kali Mati, yang berada dalam lahan yang dikelola Perhutani Kabupaten Malang. Peremajaan tanaman yang telah dilakukan mulai tahun.
\end{abstract}

Kata Kunci: Penebangan_hutan, sumber_air, kebutuhan_air, Sumur_injeksi

\section{PENDAHULUAN}

Kondisi yang sangat mengkawatirkan masyarakat, adalah perlu adanya upaya yang tepat agar dalam waktu relatif singkat dapat menyelamatkan sumber air tersebut. Konservasi lahan evektif untuk perlindungan sumber air, jika dilakukan dalam bentuk vegetatif, mekanis, dan konstruktif. Upaya yang dapat menimbulkan dampak tercepat dalam peningkatan debit sumber air adalah pembuatan sumur resapan (Kustamar, 2015). Namun demikian dari berbagai altenarif bentuk sumur resapan, sumur injeksi yang paling efektif karena penambahan air dilakukan langsung pada lapisan aquifer. Lapisan akuifer merupakan lapisan batuan bawah tanah terdiri dari pasir dan kerikil, yang merupakan tempat berkumpulnya airtanah. Airtanah dalam aquifer bergerak horizontal mengalir dan muncul dalam bentuk Sumber Air. Dengan demikian, maka sumur injekssi harus dilengkapi system filtrasi air hujan untuk menjamin tidak terjadinya pencemaran airtanah. Oleh karena hal tersebut dalam pembuatan Sumur Ijeksi harus dilakukan atau diawasi oleh orang yang ahli.

\section{METODE}

\section{Identifikasi Lokasi}

Identifikasi lokasi dilakukan berdasarkan peta topografi skala 1:25.000.000. Lokasi yang dimaksud meliputi: lokasi pengambilan air, sebaran lokasi pemakai air, batas administrative. Dengan peta skalatis yang dilengkapi dengan system koordinat, maka jalur termudah dan jarak antara kampus dengan lokasi kegiatan dapat diidentifikasi dengan tepat. Peta hard copy dan digital dibeli dari Pusat Pengelolaan Peta Teknik Geodesi ITN Malang.

\section{Survey Geologi}

Survey geologi dilakukan berdasarkan panduan lokasi sumber air yang akan ditingkatkan debitnya. Untuk mengetahui alternative lokasi sumur injeksi, perlu dilakukan pemetaan batuan, khususnya aquifer, dalam ahl ini meliputi: ketebalan lapisan aquifer, arah aliran airtanah, dan kapasitas debit aquifer. Alternatif lokasi sumur injeksi, ditentukan dengan orientasi bahwa jika dilakukan injeksi air hujan, maka akan berdampak terjadinya peningkatan debit sumber air yang menjadi sasaran.

\section{Survey Topografi}

Dari beberapa alternative lokasi sumur injeksi, selanjutnya diidentifikasi lokasi yang memiliki daerah tangkapan hujan / Catchment Area (DTA) yang luas sehingga menjamin terkumpulnya air hujan dalam jumlah yang cukup. 


\section{JURNAL INFOMANPRO \\ p-ISSN 2460-9609 \\ e-ISSN 2774-7956}

https://ejournal.itn.ac.id/index.php/infomanpro

vol.10 No.1 Tahun 2021, pp. 11-15

Selain luasnya Daerah Tangkapan Hujan, kemiringan topografi juga menjadi factor penting yang harus diperhatikan agar kemungkinan terjadi longsor dapat diminimalkan.

\section{Penentuan Lokasi Sumur Injeksi}

Berdasarkan luas DTA dan kemiringan topografi, alternative lokasi sumur injeksi tentu sudah semakin mengerucut. Pemilihan terakhir didasarkan factor aksesbilitas, mengingat dalam pelaksanaannya memelukan peralatan dan material yang jumlahnya cukup banyak, dalam hal ini tentu berpengaruh terhadap: anggaran, kecepatan waktu pelaksanaan, dan keamanan.

\section{Perencanaan Dimensi Sumur}

Dimensi sumur direncanakan berdasarkan kebutuhan volume tampungan untuk menampung hujan yang tertangkap dalam DTA dan tersalurkan ke sumur injeksi. Tampang sumur injeksi sebaiknya berbentuk lingkaran, namun jika terkendala kondisi lapangan, amak bentuk segi 4 dapat dipertimbangkan.

\section{Perencanaan Diameter Pipa Injeksi}

Diameter pipa injeksi direncanakan berdasarkan besar debit air hujan yang harus diinjeksikan, dan kecepatan rembesan air dalam system filterasi. Dengan demikian harus dioptimasi agar tercapai kesimbangan antara debit air hujan yang masuk ke dalam sumur, debit air yang tersalurkan melalui pipa injeksi, dan kapasitas tampungan sumur.

\section{Perencanaan Sistem Filtrasi}

Sistem filtrasi terdiri dari bagian penyaringan sampah, penyaringan matrial sedimen, dan pengendapan lumpur. Beberapa hal yang harus diperhatikan, ialah: Kemampuan dan kapasitas perbaikan kualitas air, serta kemudahan untuk dilakukan perawatan.

\section{Penyusunan Rencana Pelaksanaan}

Rencana pelaksanaan disusun bersama dengan mitra 1 (Kepala dusun), dam Mitra 2 (Kepala Desa), dengan batasan waktu maksimal 3 bulan. Dalam upaya sosilaisasi dan pelibatan masyarakat, maka kegiatan pembuatan konstruksi sumur injeksi mayoritas menggunakan tenaga masyarakat.

\section{Penyiapan material dan tenaga Kerja}

Berdasarkan dimensi konstruksi dan spesifikasi teknisnya, selanjutnya disusun kebutuhan material dan kebutuhan tenaga kerja. Dalam mengitung kebutuhan material, dilengkapi dengan urutan pengadaannya.

\section{Pelaksanaan Pekerjaan}

Pelaksanaan pekerjaan direncanakan dengan memaksimalkan penggunaan tenaga kerja dari mitra, baik yang berbayar (tenaga kerja terampil) maupun yang bersifat kerjabakti (tenaga kerja pendukung).

\section{Pembuatan Dokumen}

Dokumen kegiatan dibuat dalam 2 jenis, yaitu: laporan tertulis yang diperkuat gambar/ foto, dan dokumen Vedio. Pembuatan dokumen dilakukan sejak awal kegiatan sampai denga akhir masa kegiatan.

\section{HASIL DAN PEMBAHASAN}

Hasil yang telah dicapai sejak penandatanganan kontrak tanggal adalah telah dilakukan penyuluhan ke masyarakat serta pemuka masyarakat Kelurahan stempat telah mengerti mengapa harus dilakukan konservasi air tanah melalui imbuhan buatan dengan membangun sumur ijeksi. Mereka mengakui bahwa saat ini sumur-sumur yang ada payau akibat pemukiman mereka dahulu merupakan daerah rawa-rawa yang ditimbun serta pada saat musim hujan terjadi genangan di sekitar pekarangan rumah, diharapkan dengan adanya program Ipteks bagi masyarakat ini, mereka sangat antusias dan berharap dapat menjadi percontohan sehingga suatu saat nanti sumur injelsi dapat dibangun secara swadaya oleh masyarakat.

Pada saat pembuatan sumur injeksi, masyarakat secara seksama mengikuti cara pembuatannya mulai dari awal hingga akhir. Mereka mengatakan bahwa pembuatan sumur resapan ini sangat mudah namun memiliki manfaat yang sangat besar bagi kelangsungan tersedianya air tanah yang berkualitas apalagi di buat secara massal. Selanjutnya menurut mereka, halaman pekarangan rumahnya sudah tidak tergenang lagi oleh karena, air hujan yang berasal dari atap, ditampung di talang kemudian dialirkan melalui pipa paralon masuk ke dalam sumur. Jika terjadi permasalahan air tanah di daerah tersebut sejak lama dirasakan. Sumur-sumur yang ada tidak dapat digunakan untuk mencuci, mandi apalagi untuk memasak oleh karena terasa air payau. Setelah sumur injeksi 


\section{JURNAL INFOMANPRO \\ p-ISSN 2460-9609 \\ e-ISSN 2774-7956}

https://ejournal.itn.ac.id/index.php/infomanpro vol.10 No.1 Tahun 2021 , pp. 11-15

dialiri air hujan terjadi perubahan siknifikan yakni pada parameter warna, sebelum dan sesudah. Parameter bau, sumur injeksi sebelum dialiri air hujan berbau, sedangkan setelah dialiri air hujan tidak berbau. Pada parameter $\mathrm{pH}$ bernilai sama yakni 7. Terjadi penurunan setelah sumur injeksi dialiri air hujan pada parameter $\mathrm{NaCl}$ sebesar 25,5\%, Natrium 10,5, Klorida 10,1\%, sehingga saat ini sudah dapat dimanfaatkan untuk keperluan sehari-hari.

Sumur Injeksi merupakan sumur resapan dengan desain yang sudah disempurnakan, sehingga mampu berfungsi sebagai sumur resapan yang langsung dapat meng-injeksi air ke dalam lapisan aquifer. Sumur Injeksi dibuat dengan kedalaman hingga mencapai aquifer, sedangkan saringan air sebagai sarana kontrol kualitas air dipasang di bagian bawah dari sumur. Dengan demikian, kualitas air tetap terkontrol namun tidak memerlukan luas lahan tertentu. Material lapisan penyaring air dipilih agar dengan ketebalan relatif tipis dapat meningkatkan kualitas air hingga setara dengan kualitas air bersih. Sumur Injeksi terdiri dari bagian bagian sebagai berikut (Gambar 1).

1. Galian tanah, dengan kedalaman sampai aquifer

2. Filter air, untuk kontrol kualitas air

3. Pipa Cover, untuk pemasangan pipa kontrol kualitas air

4. Dinding Sumur

5. Tutup Sumur

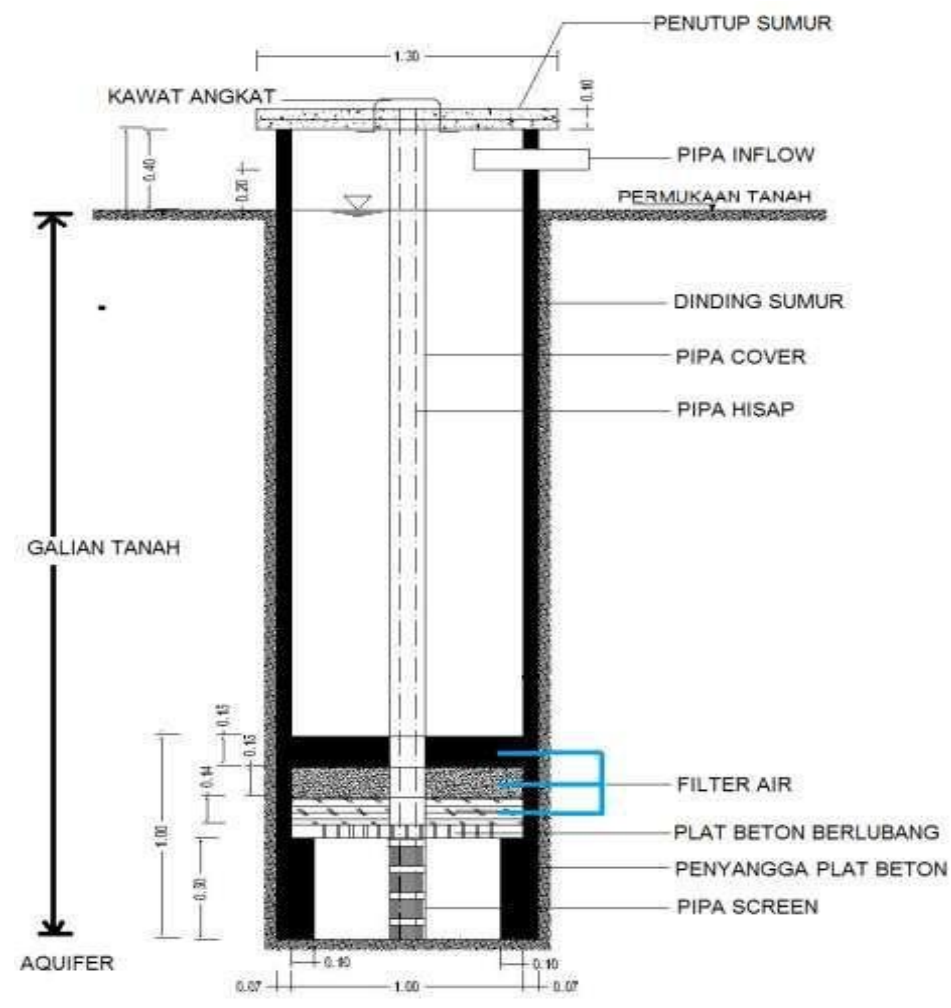

Gambar 1. Konstruksi Sumur Injeksi

\section{Detail Bagian-Bagian Penting}

1) Galian tanah hingga pencapai bagian bawah lapisan aquifer.

Galian tanah dilakukan hingga mencapai dasar dari lapisan aquifer. Hal ini bertujuan agar dapat melakukan injeksi langsung pada lapisan aquifer. Namun jika lapisan aquifer jauh lebih dalam, maka koneksi antara tampungan air dengan aquifer bisa digunakan pipa dengan diameter yang lebih kecil sehingga dalam pemasangan dapat dilakukan dengan menggunakan mesin bor tanah. 


\section{JURNAL INFOMANPRO}

p-ISSN 2460-9609

e-ISSN 2774-7956

https://ejournal.itn.ac.id/index.php/infomanpro

vol.10 No.1 Tahun 2021 , pp. 11-15

2) Filter air di bagian bawah sumur.

Filter air dipasang di bagian bawah sumur. Hal ini dimaksudkan agar tidak memerlukan lahan dengan luas tertentu, sebagai perbaikan dari sumur resapan type III dan Type IV pada SNI 03-2459-2002.

3) Plat Beton Penyaring

Plat Beton Penyaring dipasang 2 mater dari dasar aquifer, sebagai penyangga lapisan filter. Antara dasar aquifer dengan Plat Beton Penyaring akan terbentuk ruang yang cukup untuk penampung cadangan air tanah yang akan diambil melalui pipa hisap untuk monitoring kualitas air.

4) Dinding sumur bagian aquifer

Dinding sumur bagian aquifer, terbuat dari beton porus untuk memberi kesempatan proses pengisian kembali air tanah yang sudanh terambil.

5) Dinding sumur bagian atas

Dinding sumur bagian atas dipasang di atas Plat Beton Penyaring, setinggi $2 \mathrm{~m}$ terbuat dari beton masih (tidak porus), sedangkan selebihnya sampai dengan tutup sumur terbuat dari beton porus. Dinding yang masif dimaksudkan untuk memaksa agar air yang akan bercampur dengan air tanah telah merembes melalui filter air. Sedangkan didning yang porus dimaksudkan untuk memberi kesempatan air merembes melalui lapisan tanah di luar galian sumur, sebelum bersatu dengan air tanah.

6) Cover pipa hisap

Cover pipa hisap terdiri dari 2 bagian, yaitu: (1). Cover pipa hisap bagian aquifer, berupa pipa penyaring (screen pipa) yang dipasang di bawah plat beton penyaring. (2). Cover pipa bagian atas, berupa pipa dengan diameter sekitar 4" dipasang mulai plat beton penyaring hingga tutup sumur.

7) Tutup Sumur

Tutup Sumur, terbuat dari plat beton dengan ketebalan sekitar $5 \mathrm{~cm}$. Tutup sumur berfungsi untuk pengaman agar orang atau binatang tidak terperosok

\section{KESIMPULAN}

Pembuatan sumur resapan yang dilakukan oleh tim Ipeks Bagi Masyarakat dari Politeknik Negeri Ujung Pandang sangat direspon baik oleh masyarakat. Dengan adanya kegiatan pengabdian yang seperti ini menjadikan masyarakat sadar tentang pemanfaatan sumur injeksi sebagai mata air di desa Petungsewu ini.

\section{DAFTAR PUSTAKA}

Akhmad Azis, Hamzah Yusuf, Zulviyah Faisal. 2016. Konservasi Airtanah Melalui Pembuatan Sumur Resapan Air Hujan Di Kelurahan Maradekaya Kota Makassar. Journal INTEK. 2016, Volume 3 (2): $87-90$

Ananta Purwoarminta, Rachmat Fajar Lubis, dan Rizka Maria. 2019. Imbuhan Air Tanah Buatan Untuk Konservasi Cekungan Air Tanah Bandung-Soreang. Jurnal RISET Geologi dan Pertambangan, Vol.29, No.1, Juni 2019, 65-73

Bambang Soenarto, 2007. Teknik Sumur Injeksi Untuk Pengendalian Banjir dan Keperluan Lain Serta Berbagai Teknik Ekivalen Lainnya, Jurnal Sumber Daya Air, Vol. 3 No. 4 Mei 2017.

Kustamar, 2013. Konservasi Sumber Daya Air. Buku Monograf. Dream Litera.

Kustamar, 2016. Konservasi Sumber Daya Air Di Hulu DAS. Temu Ilmiah IPLBI 2016

Kustamar, dkk. 2017. Strategy To Increase Absorption Well Capacity. Journal of Technology and Sciences. Vol 1 no 1 
JURNAL INFOMANPRO

p-ISSN 2460-9609

e-ISSN 2774-7956

https://ejournal.itn.ac.id/index.php/infomanpro

vol.10 No.1 Tahun 2021 , pp. 11-15

Kustamar, dkk. 2018. The Development of the Conservative Village Model in the effort of the Water Resources in The Upstream Brantas River International Journal of GEOMATE Vol.15, Issue 50. 